\title{
Unmet health care needs and medical out-of-pocket expenses of SSI children
}

\author{
Anne DeCesaro ${ }^{\mathrm{a}}$ and Jeffrey Hemmeter ${ }^{\mathrm{b}, *}$ \\ ${ }^{\mathrm{a}}$ Office of Management and Budget, Washington, DC, USA \\ ${ }^{\mathrm{b}}$ Social Security Administration, Office of Retirement and Disability Policy, Office of Program Development and \\ Research, Baltimore, MD, USA
}

Received 4 February 2009

\begin{abstract}
Children with disabilities may have substantial health care needs due to their physical, mental, or emotional impairments. For many, taking care of these needs is critical to prevent further deterioration in their health and to promote the successful transition to life as an adult. In this paper we examine the unmet health care needs and medical out-of-pocket (MOOP) expenses for a subgroup of children with disabilities - those collecting Supplemental Security Income (SSI) payments. Using the National Survey of SSI Children and Families (NSCF), we find that: (1) only 9 percent of SSI children report delaying or going without health care in the year before the interview and 24 percent report MOOP expenses; (2) Medicaid insurance reduces both the incidence of unmet needs and MOOP expenses for SSI children; (3) those with an unmet need have higher MOOP expenses and receive lower SSI payments; and (4) the vast majority of MOOP expenses are substantially less than SSI payments for most child recipients. In total, this research shows fairly good coverage of the medical needs and expenses of SSI youth before they transition to adulthood.
\end{abstract}

Keywords: Children, Supplemental Security Income, medical out-of-pocket expenditures, unmet needs

\section{Introduction}

The Supplemental Security Income (SSI) program provides cash payments to disabled children because their needs are "often greater than those of non-disabled children" (House Report 92-231 [28, p. 2]) and because they help the family cope with lost wages and medical expenses beyond the coverage of Medicaid, for which many children on SSI are categorically eligible (Senate Report 104-096). In this paper we analyze two related concepts which SSI, along with Medicaid, is designed to help reduce among poor families with disabled children: unmet health care needs and medical out-of-pocket (MOOP) expenses.

*Address for correspondence: Jeffrey Hemmeter, Social Security Administration, Office of Retirement and Disability Policy, Office of Program Development and Research, 6401 Security Boulevard, Baltimore, MD 21235, USA. Tel.: +1 410597 1815; E-mail: jeffrey. hemmeter@ssa.gov.
While unmet health care needs measure the use and availability of health care services, medical out-ofpocket expenses measure the costs of those services over-and-above any costs covered by insurance and/or Medicaid. Together, unmet health care needs and MOOP expenses can help identify not only whether or not a child is receiving medical care, but the financial burden any received care places upon the family. Specifically, we use the National Survey of SSI Children and Families (NSCF) to describe the individual and household characteristics that are correlated with the presence of unmet health care needs and medical out-of-pocket expenses.

Our measures of unmet needs and MOOP expenses include a broad classification of general medical health needs including, but not limited to, hospital stays, doctor visits, prescription drugs, and mental health and substance abuse treatments. While much research has been done describing how the characteristics of children in the general population are related to the presence of 
unmet health care needs and MOOP expenses, little research has specifically considered children receiving SSI. Because most children on SSI have health insurance, primarily through Medicaid, we explore which other factors prevent the medical needs of child SSI recipients from being met and what factors are associated with MOOP expenses. This paper begins to develop a profile of SSI children which policymakers can use to potentially identify ways to improve access to health care among this population. Additionally, this paper provides insight to policymakers about the medical needs of SSI youth as they prepare for the transition to adulthood.

\section{SSI children's program}

SSI is a federal means-tested income supplement program authorized by Title XVI of the Social Security Act. Administered by SSA and funded by general tax revenues, the program is designed to help the aged, blind, and disabled who have little or no income, including children. A disabled child is defined by the presence of "a medically determinable physical or mental impairment which results in marked and severe functional limitations, and which can be expected to result in death or which has lasted or can be expected to last for a continuous period of not less than 12 months" (Public Law 104-193). More specifically, a "marked and severe functional limitation" means that the disability has to meet the severity level of SSA's child medical listings, taking into account functional limitations (such as cognitive, social, and personal functions as well as the ability to concentrate and complete tasks). ${ }^{1}$ At age 18 , the disabling condition is reevaluated using adult criteria emphasizing the ability to engage in substantial gainful activity (SGA); if the child is not disabled under the adult criteria, payments are terminated.

As a means-tested program, SSI recipients also must have limited income and resources. For children, countable income is the sum of the child's earned, unearned, deemed, and in-kind income after certain exclusions. Excluded income sources include, but are not limited to, the first $\$ 65$ of earned income per month and half of the child's remaining earned income, the first $\$ 20$ of any unearned income received in a month, stateor locally funded need-based assistance, and income set

\footnotetext{
${ }^{1}$ See the following link for a listing of impairment codes: http:// policy.ssa.gov/poms.nsf/lnx/0426510015.
}

aside or being used to pursue a plan for achieving selfsupport. $^{2}$ Deemed income, typically accounting for the largest part of a child's income, is derived from the parents' countable income after exclusions are made to allow for the needs of other household members. Deeming also applies to resources - items that can be owned - and includes a number of exclusions for the value of a home, pensions, household goods, and personal effects. A child cannot have countable resources in excess of $\$ 2,000$, including any deemed countable resources from parents. Unlike income, which reduces the benefit amount, exceeding the resource threshold completely disqualifies an individual from assistance. SSI recipients receive payments based on the federal benefit rate less the value of countable income (i.e., post-exclusion income) until the payment becomes zero. Additionally, several states supplement the federal SSI payment. For more information on the SSI program, see Davies, Rupp, and Wittenburg [4].

\subsection{SSI-Medicaid connection}

While enrollment in Medicaid is not automatic, most SSI recipients are covered by state administered Medicaid. Thirty-two states and the District of Columbia allow the Medicaid determination to be made by the federal government using federal SSI standards. The remaining 17 states make the determination at the state or local level with seven using the federal SSI standard, the rest relying on state-established criteria. State criteria for determining Medicaid eligibility may not be more restrictive than the state's January 1972 medical assistance standards and tends to cover all SSI recipients. ${ }^{3}$

The Medicaid benefits package for children receiving SSI covers the majority of medical and health care needs for this group. Specifically, Medicaid provides coverage for medically necessary services and additional screening through the Early Periodic Screening, Diagnosis, and Treatment, or EPSDT, program [35]. For children, Medicaid has been found to be "equal if not better" than some private plans at servicing the health needs of children and protecting vulnerable families from excessive medical out-of-pocket expenses [6]. Because the Medicaid program is intended to be the

\footnotetext{
${ }^{2}$ For more information on the treatment of income and resources, see the Annual Report of the Supplemental Security Income Program [32].

${ }^{3}$ See SSA's State Assistance Programs for SSI Recipients for specific details on individual state criteria and coverage.
} 
payer of last resort it is possible, although not likely, for a child to also have another form of insurance. However, as the payer of last resort, Medicaid fills the gap between the primary insurance and Medicaid coverage, essentially ensuring all Medicaid recipients are eligible for the same basic services.

Medicaid regulations have recently been expanded allowing states to implement cost sharing mechanisms such as deductibles and co-payments for certain services. However, children under age 18 on SSI are explicitly excluded from this provision and cannot be expected to contribute toward covered services (Public Law 109-171). Nonetheless, there are additional medical-related expenses beyond the medically necessary costs covered by Medicaid that parents and guardians of disabled children are expected to cover, such as special therapies or assistive devices. A previous study by the former General Accounting Office, for example, suggests that families incur additional disability related costs from "home-related services (extra telephone and utility charges and home modification), certain supplies (diapers needed by a disabled child who is beyond the usual age for using them and special diet or formula and clothing), respite care, over-the-counter medications for disability-related conditions, and expenses related to the purchase or modification of a vehicle beyond what a family would normally spend" $[8$, p. 42].

Contrary to the hypothesis that children apply to SSI for Medicaid benefits, Duggan and Kearney [7] found no evidence of SSI enrollment impacting health insurance coverage. They found that most new child SSI recipients had health insurance from Medicaid or another source such as SCHIP, the State Children's Health Insurance Program, at the time of enrollment. Established in 1996, SCHIP is a sometimes less comprehensive form of public insurance for children in families above the Medicaid income levels, but still unable to secure health insurance on their own or through an employer. The low income and resource limits and disability requirements of SSI effectively ensure the vast majority of recipients are enrolled in Medicaid, not SCHIP [6].

\section{Related literature}

This paper centers around two related concepts, unmet health care needs and medical out-of-pocket expenses. Unmet needs identify delayed or foregone health care while MOOP expenses measure how much of the child's medical expenses the family was respon- sible for covering. The concept of unmet health care need that is prevalent in the literature focuses on not receiving a needed service, therapy, or medication. This type of need often indicates limited access to care the service exists and the patient needs it, but he or she does not receive it (see Newacheck et al. [21] for a review of the literature). This definition is utilized by the two primary sources of data in this field of research, the National Health Interview Survey (NHIS) and the National Survey of Children with Special Health Care Needs (NSCSHCN), each of which ask if there is a health need that went unfulfilled. ${ }^{4}$

Using this definition and the NHIS, Newacheck et al. [21] found that 1.1 to 1.6 percent of children in the United States experienced an unmet medication or medical care need in the mid-1990s. ${ }^{5}$ Maag [17], also using the NHIS, reports a much higher incidence of unmet need - 12 percent - among children with functional disabilities.

Newacheck et al. [24] highlight the importance of health insurance in reducing the presence of unmet health care needs, but also indicate that, in and of itself insurance is not sufficient to eliminate those needs. Other researchers have also found that Medicaid reduces the costs of care and increases access to needed services [16]. Heck and Parker [10] found that children in lower-socioeconomic status, single-parent households were less likely to experience unmet health needs compared to lower-socioeconomic status, twoparent families due to their higher Medicaid enrollment.

Other factors can also impact the receipt of needed medical care. Sloper and Turner [30] examined the service needs of severely physically disabled children and found that high levels of unmet health care needs were associated with "high level of strain from life events" such as parental instability. Earlier research by Newacheck et al. [22] identified other barriers to receiving appropriate medical care such as transportation, language, child care, and provider availability issues.

Two studies have focused on the needs of the SSI child population, which is both low-income and disabled. As part of a study of whether fee-for-service or

\footnotetext{
${ }^{4}$ The data used for this analysis, the National Survey of SSI Children and Families (NSCF), borrowed many of its interview questions from these surveys, including the question on unmet health care needs, which came directly from the NSCSHCN. See Appendix A for the wording of the questions in the NSCF and the NHIS and NSCSHCN.

${ }^{5}$ When unmet dental care needs are included, over 7 percent of children were found to have an unmet need [21]. The most common unmet need type was for dental care (5.3 percent).
} 
managed-care Medicaid services provided better support to children on SSI in the District of Columbia, Mitchell and Gaskin [19] found that 8.9 percent of children on SSI reported a physician-, hospital-, or emergency department-based unmet need; 2.7 percent reported a prescription drug-based unmet need; 6.2 percent reported an unmet home health care need; and 12.7 percent reported an unmet medical equipment need. ${ }^{6}$ They found that SSI recipients with fee-for-servicebased Medicaid were somewhat more likely to have unmet needs. Because this study was limited to District of Columbia residents it may not be nationally representative.

A second study, by Rupp et al. [5], provides a profile of the demographics, income and assets, health and disability, and health care utilization of SSI children using the nationally-representative NSCF. They found that over 90 percent of children on SSI are covered by Medicaid. They also found moderate levels of unmet health care need among those with a perceived need (especially for respite care, mental health counseling, and recreational therapy). ${ }^{7}$

Related to the concept of unmet health care needs is that of MOOP expenses. An early study by Newacheck and McManus [20] found that, for the national disabled child population, more than 60 percent of total medical charges and out-of-pocket expenses are attributed to just 10 percent of children. Newacheck et al. [23] later found using the 1999 and 2000 Medical Expenditure Panel Survey that the average disabled child has \$297 in out-of-pocket health care expenditures annually. Other analyses of MOOP expenses have primarily focused on its relation to total family income [11,16,23]. A higher level of MOOP expenses tends to be skewed toward lower income families, which could include those with an SSI recipient child. This is particularly troublesome because it not only indicates the absolute size of the financial burden, but also the scale; MOOP expenses are a much higher percentage of family income for low-income families. For children on SSI, Rupp et al. [5] found that out-of-pocket expenses among SSI children are rather low; more than 68 percent reported no medical out-of-pocket expenses. They found that

\footnotetext{
${ }^{6}$ Additionally, 19.6 percent reported an unmet dental need; 9.1 percent reported an unmet mental health specialist need; 6.1 percent reported an unmet therapy need; and 40.7 percent reported any unmet need.

${ }^{7}$ Although the Rupp et al. [5] study uses the same data set used in the current study, they focused on different questions, and did not report unmet needs other than for services and therapies.
}

only 2.7 percent of children on SSI had more than $\$ 1,000$ in MOOP expenses. Rymer et al. [28] found that the average MOOP expenses for SSI children were $\$ 11.20$ per month (about $\$ 384$ per year in 2001 dollars).

Given the differences in the levels of unmet needs and MOOP expenses between the general disabled-child population and the SSI child population, the present analysis fills in some of the gaps of our understanding of the causes of unmet health care needs and MOOP expenses. This paper provides information which can be used to help policy makers understand the health care needs of this disadvantaged group. The effect of unmet needs and MOOP expenses on the longer-term outcomes summarized by Davies, Rupp, and Wittenburg [4] is left for future work.

\section{Data}

The NSCF provides data on a range of information previously unavailable on this segment of the SSI population. It is a nationally representative survey of noninstitutionalized current and former SSI children and young adults. Over 8,700 completed interviews provide data on topics including health, functional limitations, and disability status; health care utilization, needs, and expenses; service utilization, needs, and expenses; education and training; employment and earnings; family income and assets; and health insurance.

Many of the survey questions are identical to questions in other surveys of the disabled population, for example in the NHIS and NSCSHCN. Because many of the sample members were unable to respond, either due to age or disability, proxy respondents were used, typically a parent or guardian, with those responses presented as that of the child. Data collection occurred through telephone and in-person interviews between July 2001 and July 2002. ${ }^{8}$

The NSCF sample was drawn from administrative records based on the receipt of an SSI payment in December 2000. However, because the survey was conducted in 2001 and 2002, several sample members were no longer receiving a payment at the time of the survey. To ensure the sample is relevant to the issue under study and to maintain a constant reference point in the analysis, we limit the sample to individuals who received an

\footnotetext{
${ }^{8}$ For more information on the survey design and related documentation, see Davies and Rupp [5].
} 
SSI payment in the month preceding the interview. ${ }^{9}$ In addition to the NSCF, data from the 2000 Census were merged into the data by ZIP code to obtain estimates of rural/urban status of an individual's residence. ${ }^{10}$

The sample weights provided on the NSCF file ensure the analytic sample accurately represents the SSI child population. Additionally, standard errors are presented for all estimates based on the balanced repeated replicate (BRR) weights which take into consideration the complex sampling design of the survey. The weights provided in the NSCF weight the survey respondents in 2001 and 2002 to the child SSI population in December 2000. ${ }^{11}$ The final sample consists of 3,155 children aged 0 to 17 with a weighted total of 797,958 children receiving SSI.

The two main concepts of this analysis, unmet health needs and MOOP expenses, represent different methods of measuring interrelated concepts of access and uptake of health care by SSI recipients. Self-reported MOOP expenses are gathered from questions asking how much was spent on physical care (including doctor visits, hospital stays, and prescription drugs) and mental health and substance abuse treatment in the previous 12 months. ${ }^{12}$ To be consistent with the definition of MOOP expenses, we define the presence of an unmet need as a composite of two questions in the NSCF which ask whether the child has gone without health care or prescription drugs sometime in the previous 12 months. While unmet need is a subjective measure, based on the perceptions of parents and guardians, MOOP is arguably more objective if properly reported, measuring the actual dollar amount of medical expenditures.

While most of the other variables used in this analysis were drawn directly from the survey and are fair-

\footnotetext{
${ }^{9}$ This analysis was also completed using those receiving SSI at the time the sample was drawn, December 2000, and results were consistent with the analysis presented here.

${ }^{10}$ The rural data come from Census 2000 Summary File 1 (SF 1) 100-Percent Data, downloaded from http://factfinder.census.gov last accessed June 24, 2008. To get the file, the "Download Center" page was chosen and the "All 5-Digit ZIP Code Tabulation Areas (860) choice was selected, followed by table "P2: Urban and Rural (Total Population)".

${ }^{11}$ Differences between the number of child SSI recipients included in the analysis and the number from administrative records are due to: persons that turned 18 between being selected for the survey and the survey interview; newborns that were not alive in 2000 but became recipients; and children that became ineligible or eligible for payments after sample selection but before the survey interview.

${ }^{12}$ See Appendix A for the actual wording of the questions used and a comparison to the question in the NHIS used by Newacheck et al. [21].
}

ly straightforward to interpret, health insurance status is more ambiguous. Because Medicaid functions as payer-of-last-resort, anyone responding as having Medicaid, with or without another type of insurance, was considered as having Medicaid. Non-Medicaid recipients have some form of insurance, including other forms of public insurance, but not Medicaid. For example, they may have SCHIP, military-based insurance, or public Native American-based insurance. In addition to the 3,155 final sample members, we found only 35 individuals who were uninsured at the time of the survey. ${ }^{13}$ These children were excluded from the sample because such a small group would yield unreliable estimates.

\subsection{Caveats}

There are two caveats that should be mentioned when considering the data used for this analysis. First, the measure of insurance status refers to the time of the survey while the measures of unmet health care needs and the presence of MOOP expenses refers to any time in the previous 12 months. Thus, it is possible, for example, that some individuals report having insurance but have unmet healthcare needs or MOOP expenses from an uninsured period in the previous 12 months. Appendix Table A1 presents information on the percent of individuals covered for part of the previous 12 month period. By far, the majority (96 percent) of individuals insured at the time of the survey were insured for the entire previous 12 month period. Conversely, a large fraction of the uninsured group at the time of the survey was insured in the previous 12 months. Partialyear coverage is more likely among those with unmet health care needs and MOOP expenses. Unfortunately information on the exact timing of when unmet needs and MOOP expenses occurred is not contained in our data, so precisely matching need to insurance coverage is not possible.

Second, this study makes use of survey data that may not directly correspond to what is recorded in administrative files. Specifically, we use the first (of three) proxy-reported disabilities rather than the disability under which the child is eligible for SSI and do not change Medicaid-insurance status when the child resides in a state where all SSI recipients are covered by Medicaid. Administrative data are very useful when studying the

\footnotetext{
${ }^{13}$ These individuals may have had insurance at some point during the year.
} 
effects of policies on the program population or compiling administrative statistics. However, we are describing behavior and as such it is more appropriate to use survey responses which are more closely aligned with the impairment the parent interprets as the cause of the child's needs and the medical care the parent believes is available to the child. The use of proxyreported diagnoses also maintains the parental point of view present in the other survey questions.

Additionally, research by the Urban Institute [12] has found that the vast majority of uninsured children are eligible for Medicaid or SCHIP. Thus, changing Medicaid status to match administrative records would not model the true beliefs of a parent. Of the uninsured and non-Medicaid insured individuals we found that over half reside in states where SSI recipients automatically receive Medicaid, which suggests some room for expanded program utilization.

\section{Empirical method}

To determine which characteristics are correlated with unmet needs and MOOP expenses, we describe and analyze several variables reflecting the demographics of individuals, an individual's ability to receive medical care, and proxies for an individual's need for medical care. ${ }^{14}$ We consider the following demographic characteristics: gender (male/female); age (5 or under/6 to 12/Over 12); race (white/black/other); ethnicity (Hispanic/non-Hispanic); English language (speaks English/does not speak English); living situation (twoparents/one-parent/other); parental education (less than high school/high school or equivalent/more than high school/missing); and number of household members (less than five/more than five). Most of these factors are not expected to have any effect on the presence of an unmet need or MOOP expenses but still need to be controlled for in the model.

\footnotetext{
${ }^{14}$ The previous literature on unmet health care needs largely follows a model established by Aday and Anderson [1] and subsequently developed and utilized by Newacheck et al. [21] among others (e.g. $[13,18])$. This model is based on the population at large and the language of this model can be confusing, referring to "predisposing," "need," and "enabling" factors which may not readily translate to the SSI sub-population. The child SSI population is inherently predisposed to having an unmet need due to their low income and disability. Additionally, they all technically have a need for care. To avoid confusion, and because the model is not readily applicable to MOOP expenses, we use the categories identified in the text even though the variables are the same as those commonly used in the Aday-Anderson model.
}

It is possible that certain impairments requiring more care may be more common in certain groups, leading to more unmet needs or MOOP expenses among those groups. Additionally, non-English speakers may not be able to receive needed care because of language barriers and lower educated parents may not know what care is necessary. Children in non-two parent homes may be more prone to having an unmet need due to scheduling conflicts; the more individuals there are in the household, the fewer scheduling conflicts there may be, if there are several adults.

We also consider the following characteristics which largely represent an individual's need for care: health status (poor/fair/good/very good/excellent); severity of disability (high/moderate/low or none/missing); type of disability (physical/behavioral/mental retardation/other/missing or none); and the presence of more than one type of disability. Those with more severe disabilities and those with more disabilities are more likely to need care or to pay for care; however, that may not translate into unmet needs or out-of-pocket expenses because our sample members all have health insurance of some form. It is not clear which types of disabilities need more care or would have more expenses a priori. It may be easier to identify and receive the necessary care for a physical disability for which there are specific medical devices or surgeries compared to behavioral disabilities, which tend to have a wider range of potential treatment options and may be more difficult to identify or diagnose.

We use the following variables to identify an individual's ability to receive care: poverty level (0-49/5099/100-149/over 150 ratio of income to poverty level); rural location (0-19/20-39/40-59/60-79/80-100 percent of ZIP code rural); and insurance type (Medicaid/nonMedicaid). Individuals in more rural areas may have fewer doctors available to them or there may be prohibitively long distances to the doctor's office, increasing their propensity for an unmet health care need. This may, however, lead to lower MOOP expenses if they go without the care. This may also lead to higher MOOP expenses if there are extra transportation costs, home-visit costs, or other disability- or medical-related expenses associated with receiving the necessary care.

We hypothesize that the poorer the household the more likely the child is to have an unmet need due to an inability to pay for care. However, these individuals may have lower co-pays or be eligible for more services that could lower MOOP expenses. Additionally, child SSI recipients who receive Medicaid should be less likely to have an unmet need or MOOP expenses since 
private and other public insurance plans typically do not cover as much as Medicaid at the premium levels SSI recipients can readily afford.

After describing the overall sample data, characteristics are compared by the presence of an unmet health care need and the presence of MOOP expenses. This allows us to determine how different these groups are from each other. Logistic regression is then used to estimate how different factors affect the incidence of unmet health care need and MOOP expenses among SSI children. Additionally, we use logistic regression to explore which factors are correlated with cost as the reason for having an unmet need. An ordinary least squares (OLS) regression is estimated using the natural $\log$ of medical out-of-pocket expenses as the dependent variable for those reporting a MOOP expense. We then compare the presence of MOOP expenses between those with and without unmet health care needs, as well as by the type of health insurance coverage.

In addition to questions on medical need and outof-pocket expenses, the NSCF provides an opportunity to analyze the reasons for having an unmet health care need. We provide statistics on the reasons for having an unmet health care need, with a focus on having an unmet health care need due to cost or lack of insurance. The NSCF also includes questions asking the respondent what the household would do if their income increased or decreased by $\$ 100$. These data provide limited evidence on whether SSI payments are being used to alleviate medical needs or are primarily covering other costs. It should be noted that this does not provide evidence on whether disabled children would cause an undue financial burden on their families in the absence of SSI; it only suggests what effect more or less payments may have on the family's spending habits.

\section{Results}

\subsection{Characteristics of SSI children with unmet health care needs and MOOP expenses}

Table 1 reveals that 9.5 percent of SSI children have an unmet health care need. This is much more than the previously mentioned national average for children of 1.1 to 1.6 percent [21], yet lower than that among children with disabilities [17]. Average annual MOOP expenses are $\$ 155$ overall, but among the one-quarter that have MOOP expenses, the average annual amount is $\$ 657$.
The statistics on age and gender are similar to those from administrative data; more boys than girls receive SSI and the age distribution is skewed toward older children (see, for example, SSA's Children Receiving SSI publication). Most of the SSI children live in households with one parent or a parent who is likely to only have a high school education, its equivalent, or less. Only one in four children on SSI has a parent with more than a high school education. Almost half (47 percent) are white; a slightly lower fraction are black (46 percent). Most are non-Hispanic and almost all speak English.

As shown in Table 1, most children in our sample are reported to be in fair to good health, yet most also have disabilities with high levels of severity ( 52 percent). The largest proportion of children in the survey report behavioral disabilities (40 percent). This is similar to administrative totals of the full SSI child population where 39 percent of SSI children had mental disorders other than mental retardation at this time [31]. When we compared the survey-reported disability to the child's primary disability on SSA records, we found that only 26 percent of the survey respondents have mental disorders other than mental retardation listed as their primary impairment. ${ }^{15}$

Medicaid eligibility for children receiving SSI is likely, but not automatic; 93 percent report having Medicaid insurance; the remaining 7 percent of our sample has some other form of insurance (Table 1). A sizable minority (45 percent) of SSI children live above the poverty level. Additionally, most live in a highly urban area (61 percent).

A significantly higher proportion of those with unmet needs report having MOOP expenses compared to those with no unmet need ( 37 percent vs. 22 percent), illustrating the interrelationship between these concepts. ${ }^{16}$ However, those with unmet needs pay roughly $\$ 95$ more in MOOP expenditures, indicating an attempt to meet those needs that is unsuccessful due to possible financial restraints. Compared to those without unmet needs, a significantly higher proportion of those with unmet needs are ages 5 to 12, neither white nor black, do not speak English, and live in smaller households.

\footnotetext{
${ }^{15}$ See appendix Table A2 for the distribution of administrative disabilities by survey disability. Several of the children are classified as mentally retarded or have other mental disorders for administrative purposes but report other types of disabilities on the survey. This is not surprising considering how physical disabilities are more identifiable by a parent or guardian $[3,5]$.

${ }^{16}$ All differences reported in the text are statistically significant at the 10-percent level, unless otherwise stated.
} 


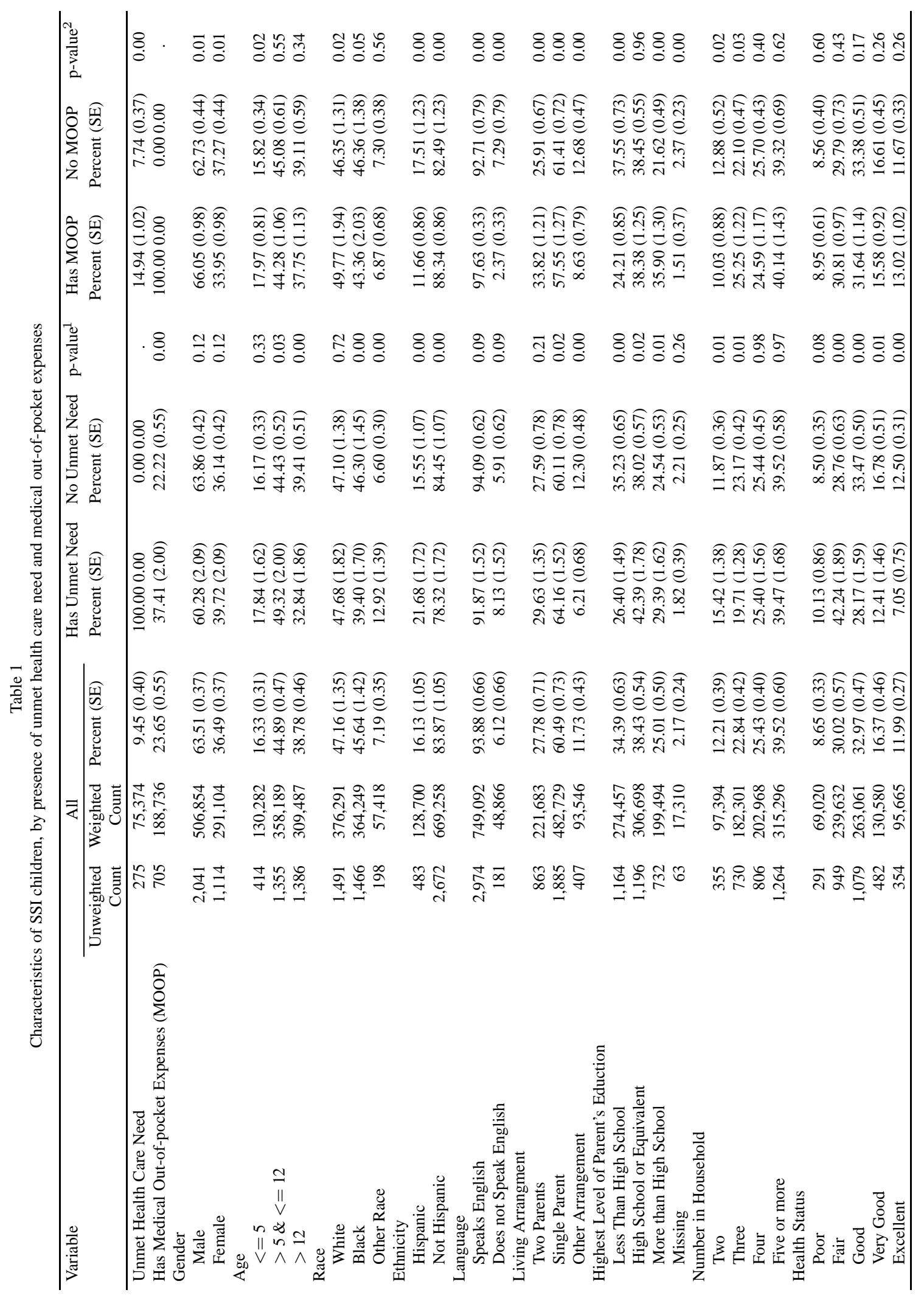




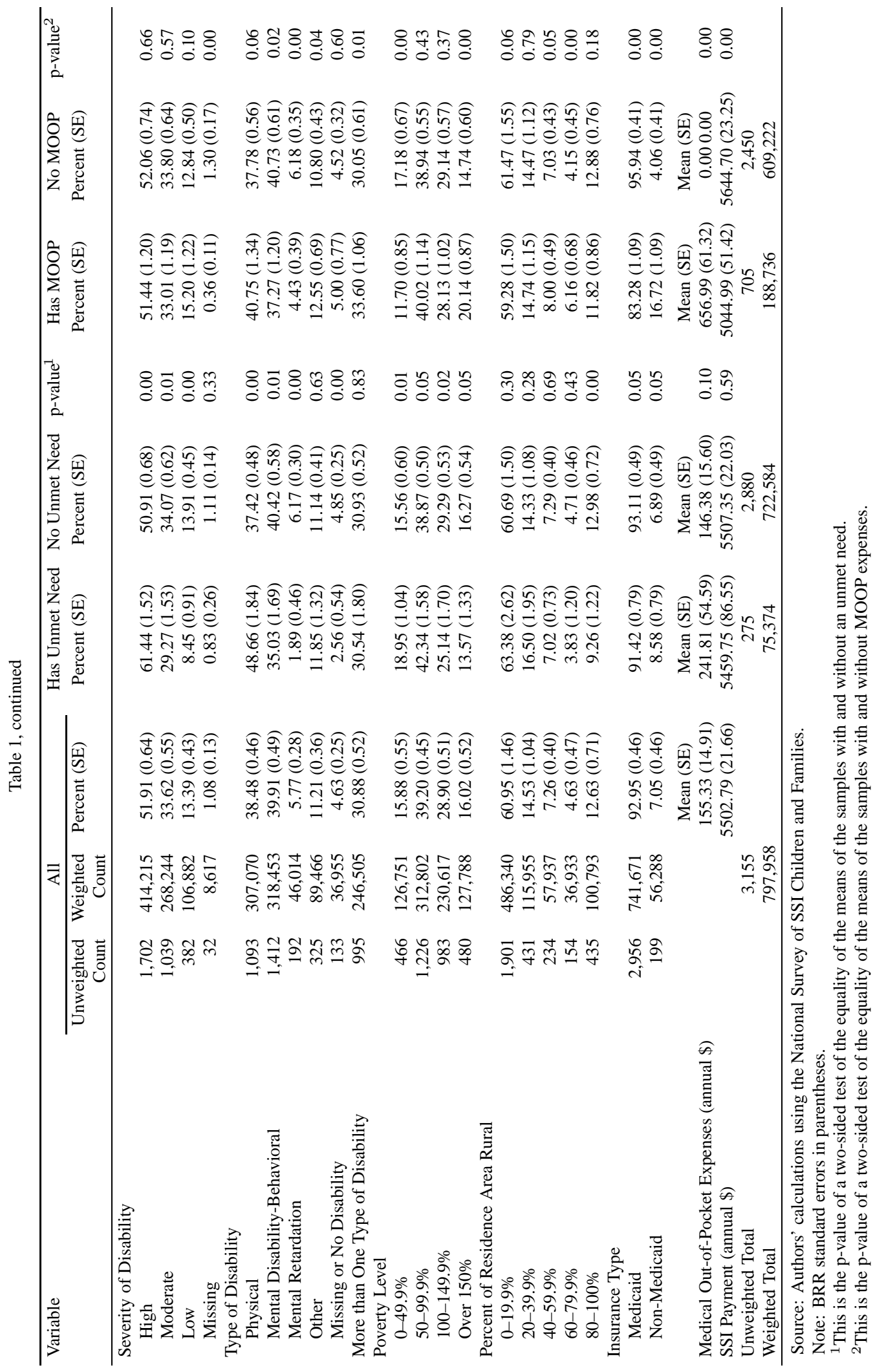


Table 2

MOOP expenses among SSI children by presence of an unmet health care need and type of insurance (column percentages)

\begin{tabular}{|c|c|c|c|c|}
\hline MOOP expenses & All & Has an unmet health care need & No unmet health care need & p-value \\
\hline \multicolumn{5}{|c|}{ Non-Medicaid Insured } \\
\hline$\%$ with No MOOP expenses & 43.93 & 30.86 & 45.63 & 0.01 \\
\hline SE & (2.65) & (4.45) & (2.91) & \\
\hline Weighted N & 24,730 & 1,996 & 22,734 & \\
\hline Unweighted $\mathrm{N}$ & 103 & 10 & 93 & \\
\hline$\%$ with MOOP expenses & 56.07 & 69.14 & 54.37 & 0.01 \\
\hline SE & (2.65) & $(4.45)$ & (2.91) & \\
\hline Weighted $\mathrm{N}$ & 31,558 & 4,472 & 27,086 & \\
\hline Unweighted $\mathrm{N}$ & 96 & 12 & 84 & \\
\hline \multicolumn{5}{|c|}{ Medicaid Insured } \\
\hline$\%$ with No MOOP expenses & 78.81 & 65.57 & 80.16 & 0.00 \\
\hline SE & $(0.55)$ & $(2.21)$ & $(0.55)$ & \\
\hline Weighted N & 584,493 & 45,181 & 539,312 & \\
\hline Unweighted $\mathrm{N}$ & 2,347 & 166 & 2,181 & \\
\hline$\%$ with MOOP expenses & 21.19 & 34.43 & 19.84 & 0.00 \\
\hline SE & $(0.55)$ & $(2.21)$ & $(0.55)$ & \\
\hline Weighted $\mathrm{N}$ & 157,178 & 23,725 & 133,453 & \\
\hline Unweighted $\mathrm{N}$ & 609 & 87 & 522 & \\
\hline \multicolumn{5}{|c|}{ Total } \\
\hline$\%$ with No MOOP expenses & 76.35 & 62.59 & 77.78 & 0.00 \\
\hline SE & $(0.55)$ & $(2.00)$ & $(0.55)$ & \\
\hline Weighted N & 609,222 & 47,177 & 562,045 & \\
\hline Unweighted $\mathrm{N}$ & 2,450 & 176 & 2,274 & \\
\hline$\%$ with MOOP expenses & 23.65 & 37.41 & 22.22 & 0.00 \\
\hline SE & $(0.55)$ & $(2.00)$ & $(0.55)$ & \\
\hline Weighted N & 188,736 & 28,198 & 160,539 & \\
\hline Unweighted N & 705 & 99 & 606 & \\
\hline
\end{tabular}

We find a higher proportion of SSI children with unmet needs have parents with a high school or equivalent level of education or more. One possible explanation is that the parents of these children have jobs with poor health insurance or inflexible work schedules leading to an inability for the child to receive all necessary care. It should again be noted that this is self-reported data on perceived unmet healthcare need. Parents with higher levels of education may be more critical of the care their child is receiving which may translate into a perception of higher levels of unmet health care need, although this is not directly testable. It has previously been found that a child's unmet mental health care needs are often undocumented due to the greater ease with which parents can identify physical disability [11]; parents with higher levels of education may be better able to discern needed care.

Children on SSI with an unmet need are slightly more likely to have non-Medicaid insurance than those with no unmet need. SSI children with unmet needs are also more likely to be in fair or poor health and have a high-severity disability, compared to children without unmet health care needs, confirming prior expectations.
SSI children with unmet needs are also more likely to be living below the poverty level. Contrary to our expectations, children on SSI with unmet needs are less likely to live in a very rural area.

As with the presence of an unmet need, there are significant differences between the characteristics of those with MOOP expenses and without MOOP expenses. Almost twice as many SSI children with MOOP expenses report having unmet health care needs, compared to those without MOOP expenses (15 percent vs. 8 percent). Among the 24 percent of SSI children reporting MOOP expenses, the average annual value was \$657. A higher percentage of those with MOOP expenses are male, non-Hispanic, and speak English compared to those without MOOP expenses. We find that SSI children with MOOP expenses are more likely to live in two-parent households and have parents with higher levels of education. They are also more likely to have a physical or "other" disability and more than one disability than children without MOOP expenses. SSI children with MOOP expenses are also less likely to have Medicaid insurance than those without MOOP expenses ( 83 percent vs. 96 percent). 
We find that those with an unmet need have higher MOOP expenses. Interestingly, the mean annual SSI payment is $\$ 600$ lower for those with MOOP expenses compared to those without MOOP expenses. This is roughly equivalent to the average level of MOOP expenditures for this group. Children with lower SSI payments may be more able to spend money on medical expenses because they are in families with higher income, although there is no reason to expect MOOP expenditures and SSI payments to be directly related given insurance coverage and differences in health needs by disability.

\subsection{Relationship between MOOP expenses and unmet health care needs}

Unmet health care needs and medical out-of-pocket expenses measure related concepts, both of which may be affected by the type of health insurance a child has. For example, the presence of an unmet need may lead a family to spend more on MOOP expenses if administrative barriers are the reasons for the need. It may also lead to less MOOP expenses if they are not informed of the necessary care. The type of insurance available may lead to different relationships. To further understand the relationship between insurance, MOOP expenses, and unmet health care needs, cross tabulations of the presence of MOOP expenses by the presence of an unmet health care need by type of insurance are presented in Table 2.

Children on SSI with Medicaid insurance are less likely to report MOOP expenses, whether or not they have an unmet health care need, than SSI children with non-Medicaid insurance. Almost 70 percent of SSI children with an unmet health care need and nonMedicaid insurance have MOOP expenses compared to 34 percent of Medicaid-insured SSI children with an unmet health care need. While a lower percentage of SSI children with no unmet health care needs have MOOP expenses, non-Medicaid insured SSI children are still more likely to have them (54 percent vs. 20 percent).

These results suggest there are significant differences in the characteristics of SSI children with and without unmet needs and MOOP expenses and that Medicaid is a strong tool in preventing MOOP expenses. The next sections focus on whether these differences remain after controlling for other factors.

\subsection{Presence of an unmet health care need}

Table 3 presents the results from the logistic regression of having an unmet health care need on our variables of interest. Odds ratios are presented for consistency with previous research and ease of interpretation. Unlike Newacheck et al. [21], who studied the general population, we find that males in the SSI child population are less likely to have an unmet health care need, all else equal, that Hispanic children on SSI are more likely to have an unmet health care need than non-Hispanic children on SSI, and that children on SSI of races other than white or black are more likely to have an unmet health care need than white children. We also find that SSI children living in two-parent homes are more likely to have an unmet health care need than those living in other living arrangements. Consistent with Newacheck et al., SSI children with less highly educated parents are less likely to have a reported unmet health care need.

Considering health status, we find evidence that better health reduces the likelihood of having an unmet health care need. Relative to SSI children in poor health, SSI children in good, very good, and excellent health are less likely to have an unmet health care need. Interestingly, SSI children in fair health are more likely to have unmet need compared to SSI children in poor health. Newacheck et al. [21] find a much larger effect of poor health in the general population. The odds of an SSI child with a high-severity disability having an unmet health care need are 43 percent higher than the odds of those with a moderate disability. The odds of a mentally retarded SSI child having an unmet health care need are 75 percent lower than those with a physical disability. SSI children with behavioral mental impairments have 19 percent lower odds than those with physical disabilities.

Health insurance presents some of the largest disparities. Those with non-Medicaid insurance are more likely to have an unmet health care need than those on Medicaid. The odds of non-Medicaid insured SSI children having an unmet health care need are almost 1.5 times higher than those of Medicaid-insured SSI children. Similar to other studies, there is a poverty connection to unmet needs; our analysis reveals that as the income level rises relative to poverty, the likelihood of an unmet need decreases. SSI children in very rural areas (80 to 100 percent) are also less likely than those in urban areas to have an unmet health care need. 
Table 3

Odds ratios from logit regression of unmet health care needs among SSI children

\begin{tabular}{|c|c|c|}
\hline \multirow{2}{*}{$\begin{array}{l}\text { Variable } \\
\text { Demographic Factors }\end{array}$} & \multicolumn{2}{|c|}{ Unmet Need } \\
\hline & & \\
\hline \multicolumn{3}{|l|}{ Gender (Reference is Female) } \\
\hline Male & $0.85^{*}$ & $(0.08)$ \\
\hline \multicolumn{3}{|l|}{ Age (Reference is $>5 \&<=12$ ) } \\
\hline Age $<=5$ & 0.85 & $(0.11)$ \\
\hline Age $>12$ & 0.87 & $(0.08)$ \\
\hline \multicolumn{3}{|l|}{ Race (Reference is White) } \\
\hline Black & 0.90 & $(0.07)$ \\
\hline Other Race & $2.06^{* * *}$ & $(0.26)$ \\
\hline \multicolumn{3}{|l|}{ Ethnicity (Reference is Non-Hispanic) } \\
\hline Hispanic & $1.32^{* * *}$ & $(0.13)$ \\
\hline \multicolumn{3}{|l|}{ Language (Reference is Speaks English) } \\
\hline Does not Speak English & 1.10 & $(0.21)$ \\
\hline \multicolumn{3}{|l|}{ Living Arrangment (Reference is Two Parents) } \\
\hline Single Parent & 0.89 & $(0.09)$ \\
\hline Other Arrangement & $0.51^{* * *}$ & $(0.08)$ \\
\hline \multicolumn{3}{|c|}{ Highest Level of Parent's Eduction (Reference is High School or Equivalent) } \\
\hline Parent Has Less Than High School Education & $0.62^{* * *}$ & $(0.05)$ \\
\hline Parent Has More than High School Education & 1.08 & $(0.09)$ \\
\hline Missing Parent Education & $0.53^{* * *}$ & $(0.12)$ \\
\hline \multicolumn{3}{|l|}{ Number in Household (Reference is Less than Five) } \\
\hline Five or more & 0.96 & $(0.07)$ \\
\hline \multicolumn{3}{|l|}{ Health Factors } \\
\hline \multicolumn{3}{|l|}{ Health Status (Reference is Poor Health) } \\
\hline Fair Health & $1.37^{* *}$ & $(0.17)$ \\
\hline Good Health & $0.79^{*}$ & $(0.10)$ \\
\hline Very Good Health & $0.70^{*}$ & $(0.14)$ \\
\hline Excellent Health & $0.59^{* * *}$ & $(0.08)$ \\
\hline \multicolumn{3}{|c|}{ Severity of Disability (Reference is Moderate Severity) } \\
\hline High Severity Disability & $1.43^{* * *}$ & $(0.13)$ \\
\hline Low Severity/No Disability & 0.90 & $(0.15)$ \\
\hline Missing Severity & 0.92 & $(0.34)$ \\
\hline \multicolumn{3}{|l|}{ Type of Disability (Reference is Physical Disability) } \\
\hline Mental Disability-Behavioral & $0.81^{* *}$ & $(0.08)$ \\
\hline Mental Disability-Retardation & $0.25^{* * *}$ & $(0.07)$ \\
\hline Other Disability & 0.90 & $(0.13)$ \\
\hline Missing or No Disability & $0.61^{* *}$ & $(0.15)$ \\
\hline \multicolumn{3}{|l|}{ More than One Type of Disability (Reference is No) } \\
\hline Yes & 0.99 & $(0.09)$ \\
\hline \multicolumn{3}{|l|}{ Ability to Receive Care } \\
\hline \multicolumn{3}{|l|}{ Poverty Level (Reference is Less than $50 \%$ ) } \\
\hline $50-99.9 \%$ of Poverty Level & 0.89 & $(0.08)$ \\
\hline $100-149.9 \%$ of Poverty Level & $0.74^{* * *}$ & $(0.08)$ \\
\hline Over $150 \%$ of Poverty Level & $0.67^{* * *}$ & $(0.08)$ \\
\hline \multicolumn{3}{|c|}{ Percent of Residence Area Rural (Reference is Less than 20\%) } \\
\hline 20-39.9\% Rural Area & 1.09 & $(0.16)$ \\
\hline 40-59.9\% Rural Area & 1.05 & $(0.11)$ \\
\hline 60-79.9\% Rural Area & 0.87 & $(0.30)$ \\
\hline $80-100 \%$ Rural Area & $0.79^{*}$ & $(0.10)$ \\
\hline \multicolumn{3}{|l|}{ Insurance Type (Reference is Medicaid) } \\
\hline Non-Medicaid & \multirow{2}{*}{\multicolumn{2}{|c|}{$\begin{array}{l}1.50 \\
797,958\end{array}$}} \\
\hline Weighted Total & & \\
\hline Subpop Obs & \multicolumn{2}{|c|}{3,155} \\
\hline
\end{tabular}

Source: Authors' calculations using the National Survey of SSI Children and Families.

Notes: BRR standard errors in parentheses

${ }^{*}$ significant at $10 \% ;{ }^{* *}$ significant at $5 \% ;{ }^{* * *}$ significant at $1 \%$. 
Table 4

Logit odds ratios and OLS coefficients of medical out-of-pocket expenses among SSI children

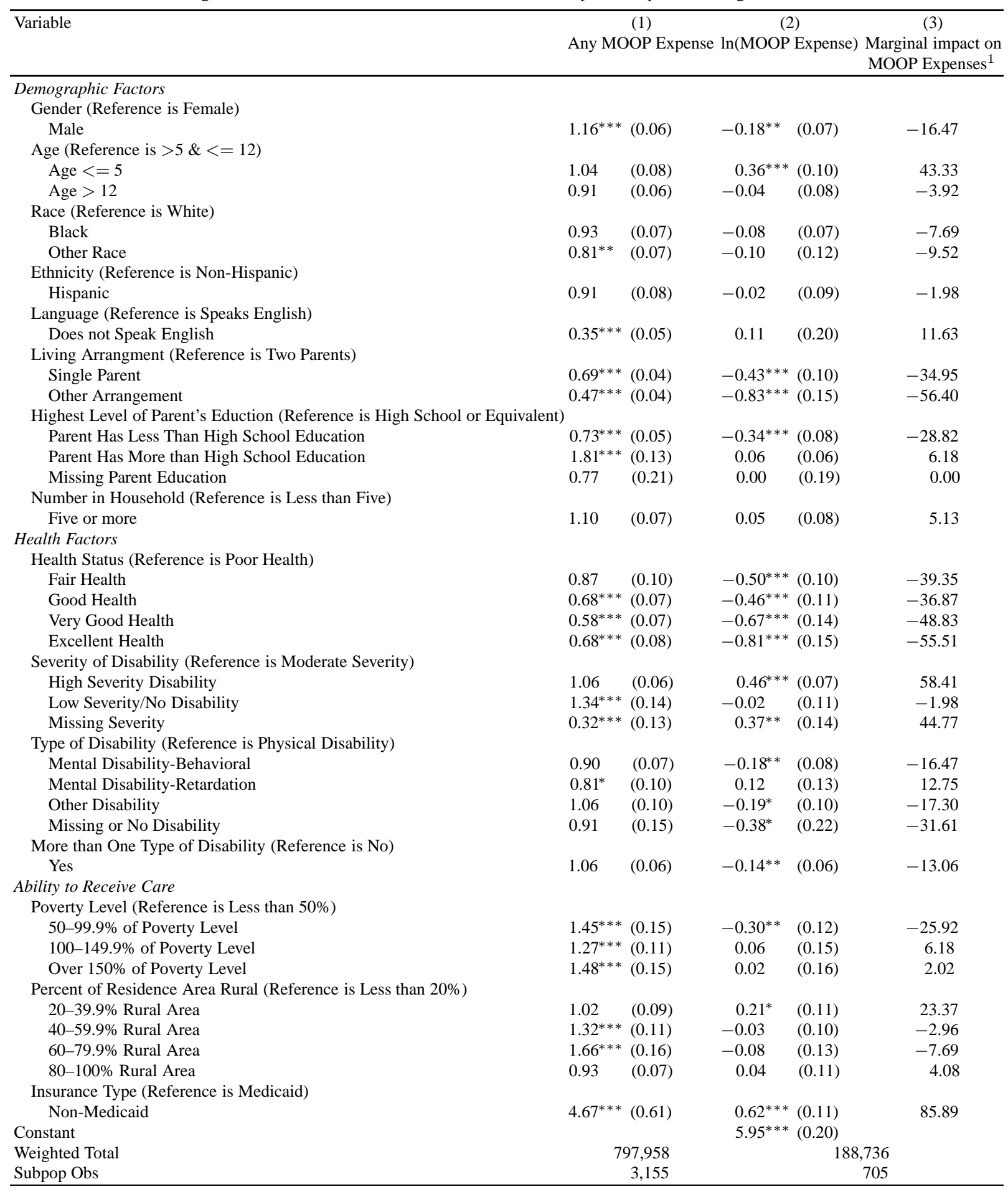

Source: Authors' calculations using the National Survey of SSI Children and Families.

Notes: BRR standard errors in parentheses.

${ }^{*}$ significant at $10 \%$; ${ }^{*}$ significant at $5 \%$; ${ }^{* *}$ significant at $1 \%$.

${ }^{1}$ This is $100 *(\exp (\beta)-1)$ where $\beta$ is from column (2). 


\subsection{Cost as a reason for unmet health care needs}

Tabulations of reasons for having an unmet need among the 275 unweighted cases which had an unmet health care need (not shown) indicate that simply having insurance does not alleviate all unmet health care needs. Thirty-eight percent of those with reported unmet health care needs indicate cost as a reason for having an unmet health care need. ${ }^{17}$ Sixty-eight percent of children with reported unmet health care needs report administrative reasons for the need, such as not being able to locate a provider or unable to schedule an appointment.

\subsection{Presence of medical out-of-pocket (MOOP) expenses}

It was shown above that children with Medicaid insurance were less likely to have MOOP expenses than their peers with non-Medicaid insurance. We find that not having Medicaid insurance remains strongly correlated with MOOP expenses even when demographic factors, health status, and other measures of ability to receive care are controlled for (Table 4, Column 1). The odds of SSI children with non-Medicaid insurance having a MOOP expense are almost five times those of SSI children with Medicaid insurance, all else equal.

Children in poor or fair health and those with low severity disabilities are also more likely to have MOOP expenses. The odds of an SSI child with a low-severity or no reported disability reporting MOOP expenses are 34 percent higher than those of an SSI child with a moderately-severe disability. There is no significant difference between SSI children with moderatelysevere disability and those with high-severity disabilities. It may be that the catastrophic medical expenses of children with more severe disabilities are covered by insurance while those with low-severity disabilities are not.

We also find several demographic characteristics are correlated with having a MOOP expense. Males, children who speak English, children in two parent homes, and children with parents who have an education above the high school level are more likely to a MOOP expense than their peers.

\footnotetext{
${ }^{17}$ Cost as a reason for an unmet need may be due to individuals having insurance for some needs but lacking insurance for others or because they lacked insurance some time in the 12 months preceding the survey.
}

Children in higher ranges of the income distribution are also more likely to have MOOP expenses. This highlights the fact that although the concept of MOOP expenses is related to the concept of unmet need, the two are not identical. Recall that children in higher ranges of the income distribution were less likely to have an unmet need (Table 3). This reflects one difference between the MOOP expense and unmet need concepts - although a higher income may allow for spending on a disability, it may not reduce health needs all together.

\subsection{Level of MOOP expenses}

We now turn our attention to the level of medical outof-pocket expenses. While only 24 percent of SSI children report having MOOP expenses (Table 1), the majority (52 percent) of these children have yearly MOOP expenses of less than $\$ 200$ (Fig. 1). Less than a quarter (23 percent) has $\$ 500$ or more and only 10 percent of those reporting any MOOP have expenses over $\$ 1000$. On average, SSI children with MOOP expenses had $\$ 657$ in MOOP expenses in the 12 months prior to the NSCF interview, or an average of $\$ 55$ per month (Table 1).

In the context of the entire SSI child population, SSI children average only $\$ 155$ in MOOP expenses per year, or about $\$ 13$ per month, although three quarters do not have any MOOP expenses. This is about $\$ 20$ less per month (in inflation adjusted dollars) than the level of extra health care expenses of SSI children in 1978 [28]. Whether this is due to lower actual MOOP expenses, fewer needs for services, changes in the prices of those services, better Medicaid coverage, or changes in the types of health care needed and used is beyond the scope of this paper. ${ }^{18}$

To better understand the relationship between MOOP expenses and other factors, we ran an OLS regression of the natural $\log$ of the amount of MOOP expenses on our explanatory variables. The sample is restricted to only those having a MOOP expense of at least one dollar, restricting the sample to 705 unweighted cases. The coefficients and standard errors are presented in column 2 of Table 4. Since the dependent variable is a natural $\log$ and all the variables are dummy variables, to interpret the results as percentage changes in MOOP expenses, the coefficients need to be adjusted to reflect

\footnotetext{
${ }^{18}$ The difference in the wording of the questions and what is included may also impact this result, although the measures compared are very similar.
} 


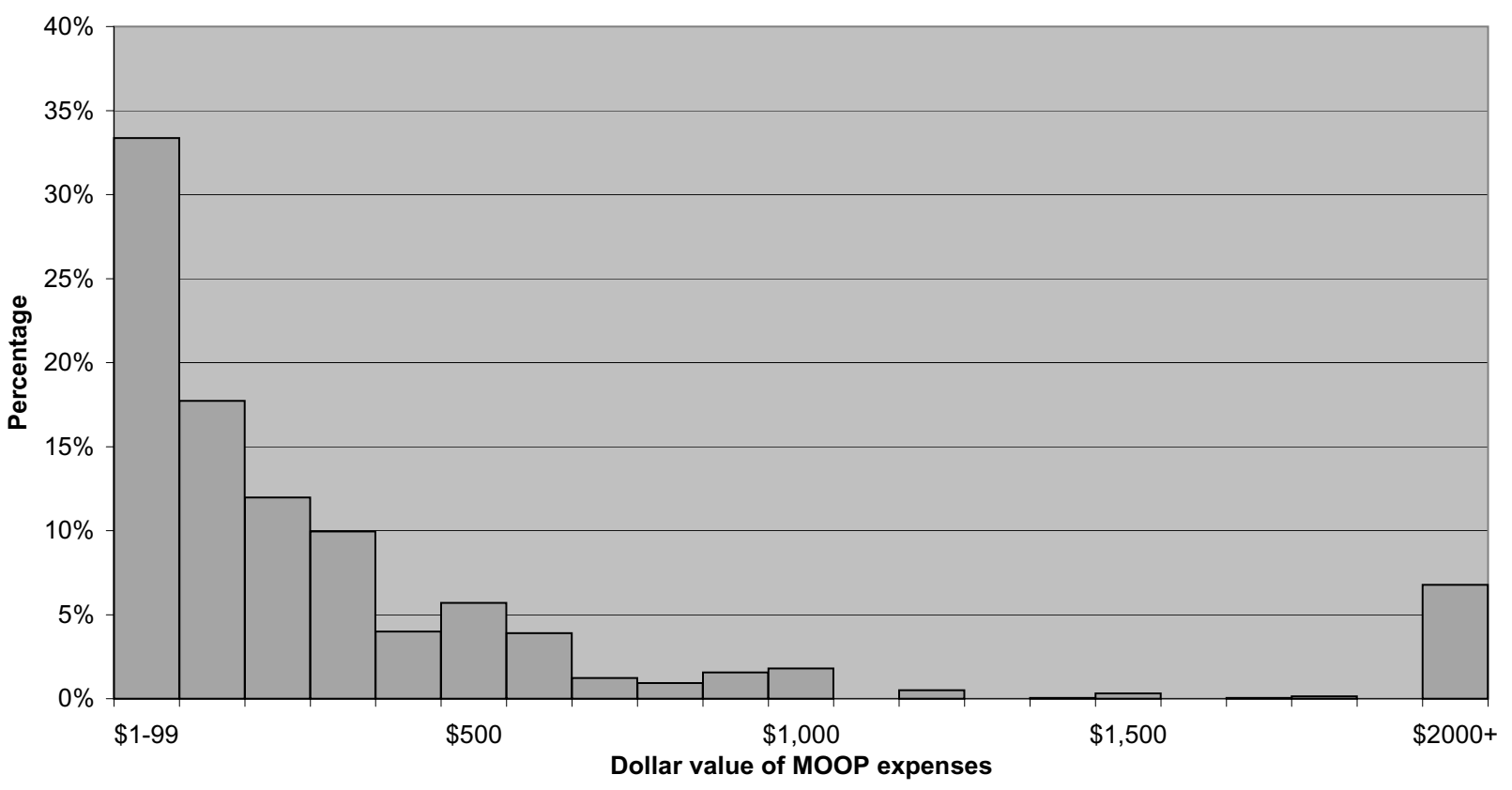

Source: Authors' calculations using the National Survey of SSI Children and Families

Fig. 1. Distribution of MOOP Expenses for SSI Children (weighted, conditional on having a MOOP expense and SSI, in $\$ 100$ increments).

the nonlinear relationship in the semi-logarithmic regression [9,33]. ${ }^{19}$ These adjusted values are presented in column 3.

Among those with MOOP expenses, Medicaid insurance makes a large difference. Those without Medicaid have 86 percent higher MOOP expenses than those with Medicaid. SSI children with non-Medicaid insurance appear to be doubly affected by their insurance status. Not only are they much more likely to have MOOP expenses, but when they have them they are much higher.

SSI children age 5 and under and those with highseverity disabilities or with a missing disability code in the NSCF have higher MOOP expenses than their corresponding peers. Meanwhile, SSI children in nontwo-parent families, males, and children whose parents had less than a high school education were all found to have lower MOOP expenses, all else equal. Whether this is due to lower demand for health care among these groups is not readily identifiable in the data, although these results are consistent with children in homes with a higher socioeconomic status being more able to fund MOOP expenses.

SSI children in better health have lower MOOP expenses than those in poor health, with those in excel-

\footnotetext{
${ }^{19}$ This adjustment is: $100 *(\exp (\beta)-1)$.
}

lent health reporting 56 percent lower MOOP expenses than those in poor health, all else equal. Disability type is an important factor in the level of MOOP expenses. SSI children with behavioral mental disabilities have 16 percent lower MOOP expenses than SSI children with physical disabilities.

\subsection{MOOP expenses as a fraction of SSI payments}

Because child SSI payments are intended to help the family cope with the added expenses stemming from the child's disability, it is of interest to compare MOOP expenses to the SSI payment. It should be noted that some expenses not counted in our definition of MOOP expenses include modifications to automobiles or homes to accommodate the child's disability and medically-appropriate child care. SSI payments may also help these families pay for expenses that are eventually reimbursed by insurance, such as certain prescription drugs or disability related equipment.

Figure 2 shows annual MOOP expenses as a percentage of the child's annualized SSI payment. ${ }^{20}$ Although 95 percent of those reporting a MOOP expense have the value of it covered by their annual SSI amount, the vast

\footnotetext{
${ }^{20}$ The annual SSI payment assumes that same monthly amount was paid for an entire year.
} 


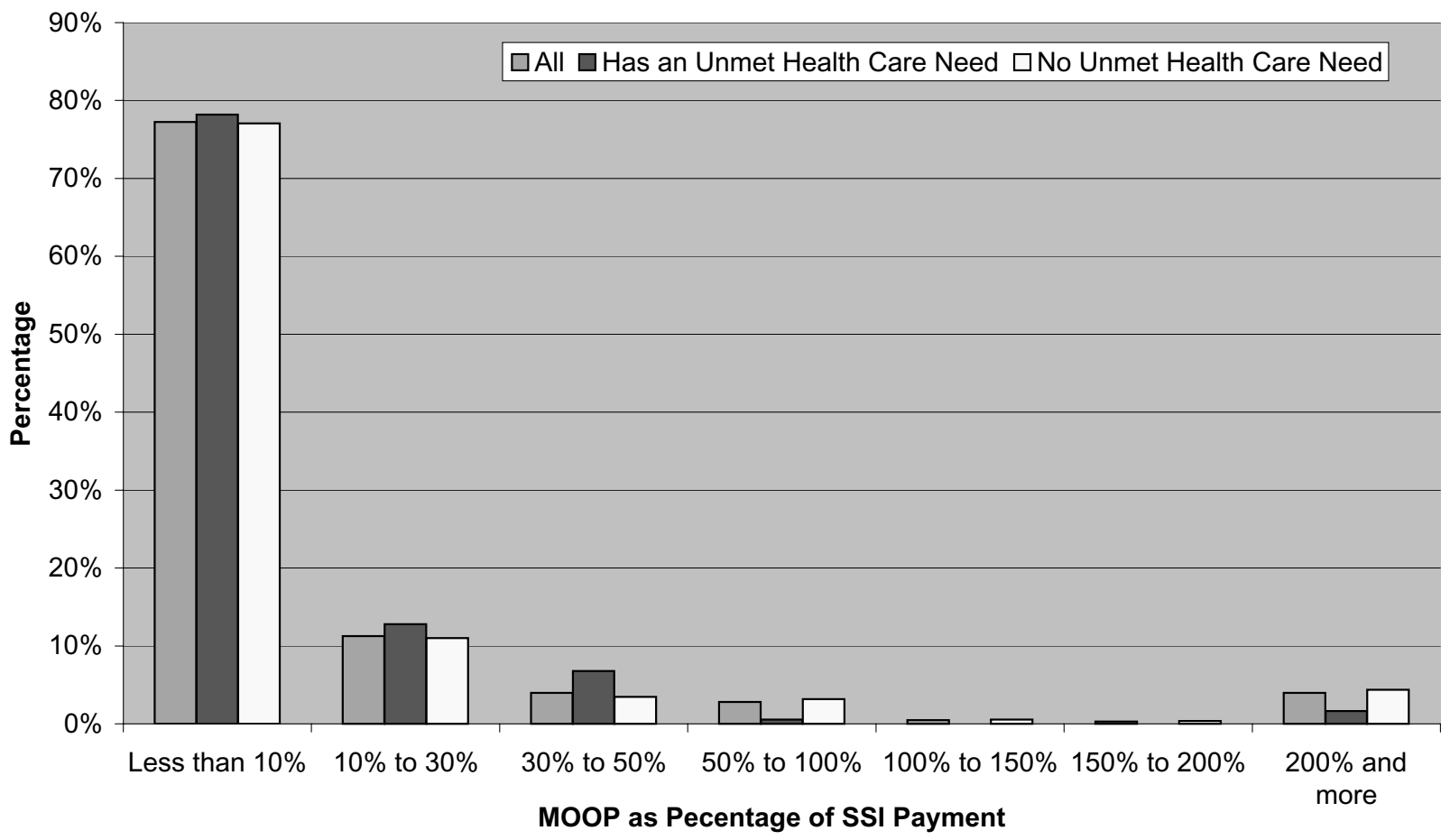

Source: Authors' calculations using the National Survey of SSI Children and Families.

Fig. 2. Percent with MOOP as a Percentage of SSI Payment Amount, by Presence of Unmet Need (weighted, conditional on having MOOP expenses).

majority (over 75 percent) of children with MOOP expenses report MOOP expenses less than 10 percent of their annual SSI payment amount. Figure 2 also shows the distribution of the MOOP-SSI ratio by unmet need status. There is no statistical difference between the fraction of those with and without an unmet health care need reporting MOOP expenses of less than 10 percent of their SSI payment.

Figure 3 reinforces the importance of Medicaid. Child SSI recipients with Medicaid insurance are not only less likely to report MOOP expenses, but among those who do, expenses are a much lower percentage of their SSI payment. Whereas 9 percent of recipients with non-Medicaid insurance report MOOP expenses above 200 percent of their SSI payment, only 3 percent of recipients with Medicaid insurance do so ( $\mathrm{p}$ value $=0.019$ ). Additionally, 81 percent of recipients with Medicaid insurance report a MOOP-SSI ratio of less than 10 percent, compared to 59 percent of nonMedicaid insured recipients ( $\mathrm{p}$-value $=0.000$ ).

\subsection{Changes in income and family expenditures}

To better understand the importance of disabilityrelated expenses in the budgets of recipients, we use questions on the NSCF that ask what a family would do if their monthly income were increased or decreased by $\$ 100$. Responses were coded by the interviewer to match an unread list of options. Additionally, respondents were asked to identify which change they would make first if more than one option was indicated. The results are presented in tables 5 (increase income by $\$ 100$ ) and 6 (decrease income by $\$ 100){ }^{21}$

Table 5 shows that overwhelmingly, respondents indicated they would spend more money on food if their income increased by $\$ 100$ (48 percent). The next most common response was to spend more money on personal items (40 percent) followed by debt reduction (15 percent). When asked on what they would first spend the initial income, the most common response was again food (39 percent) followed by personal items (21 percent). The third most common response was to first spend the increased income on other unlisted items

\footnotetext{
${ }^{21}$ Note that the questions regarding an increase or decrease in income of $\$ 100$ refer to the time of the survey but that unmet needs and MOOP expenses may have occurred any time in the previous 12 months. Because of this, the results here may be biased away from changes in disability-related expenditures.
} 


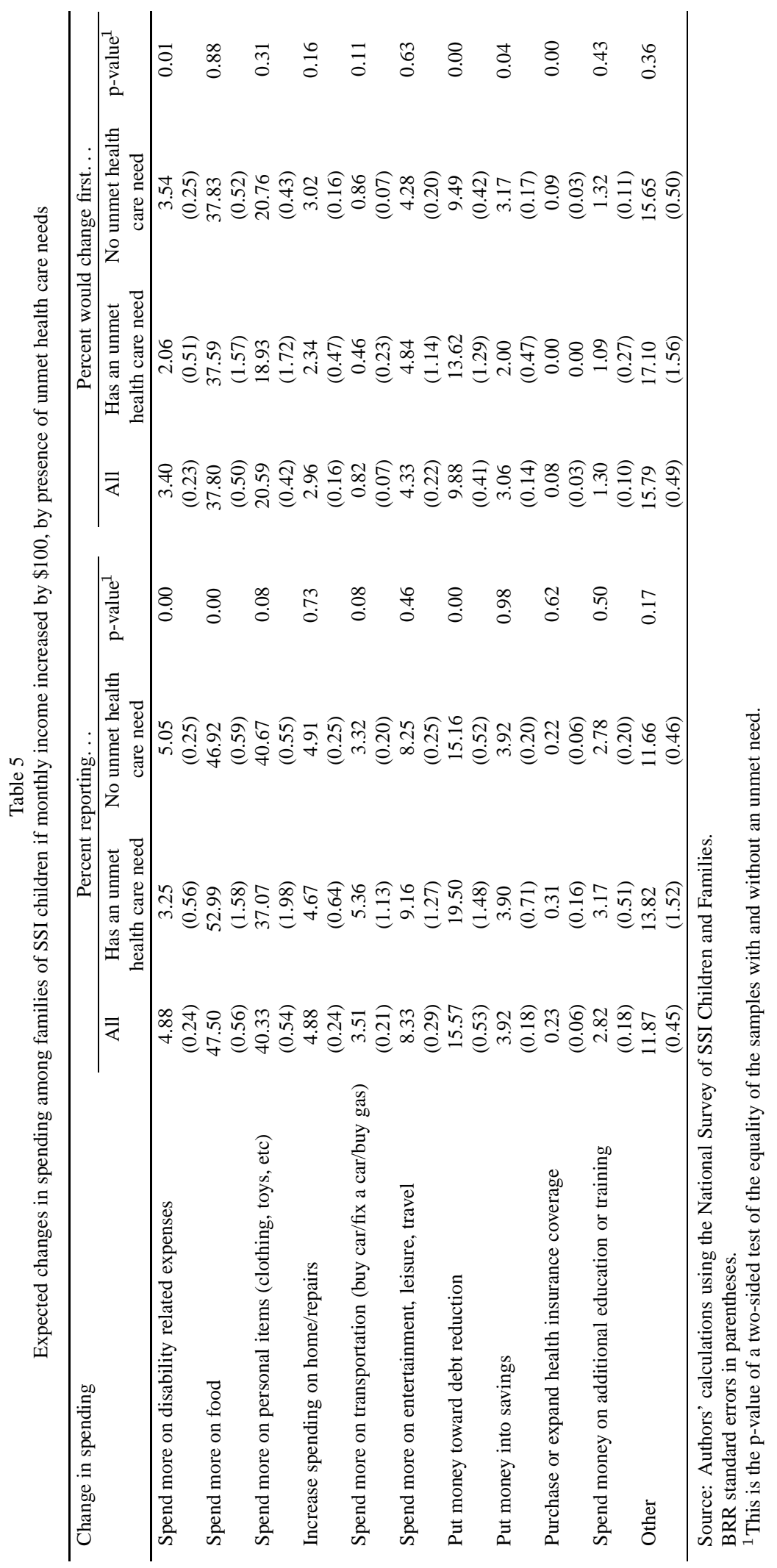




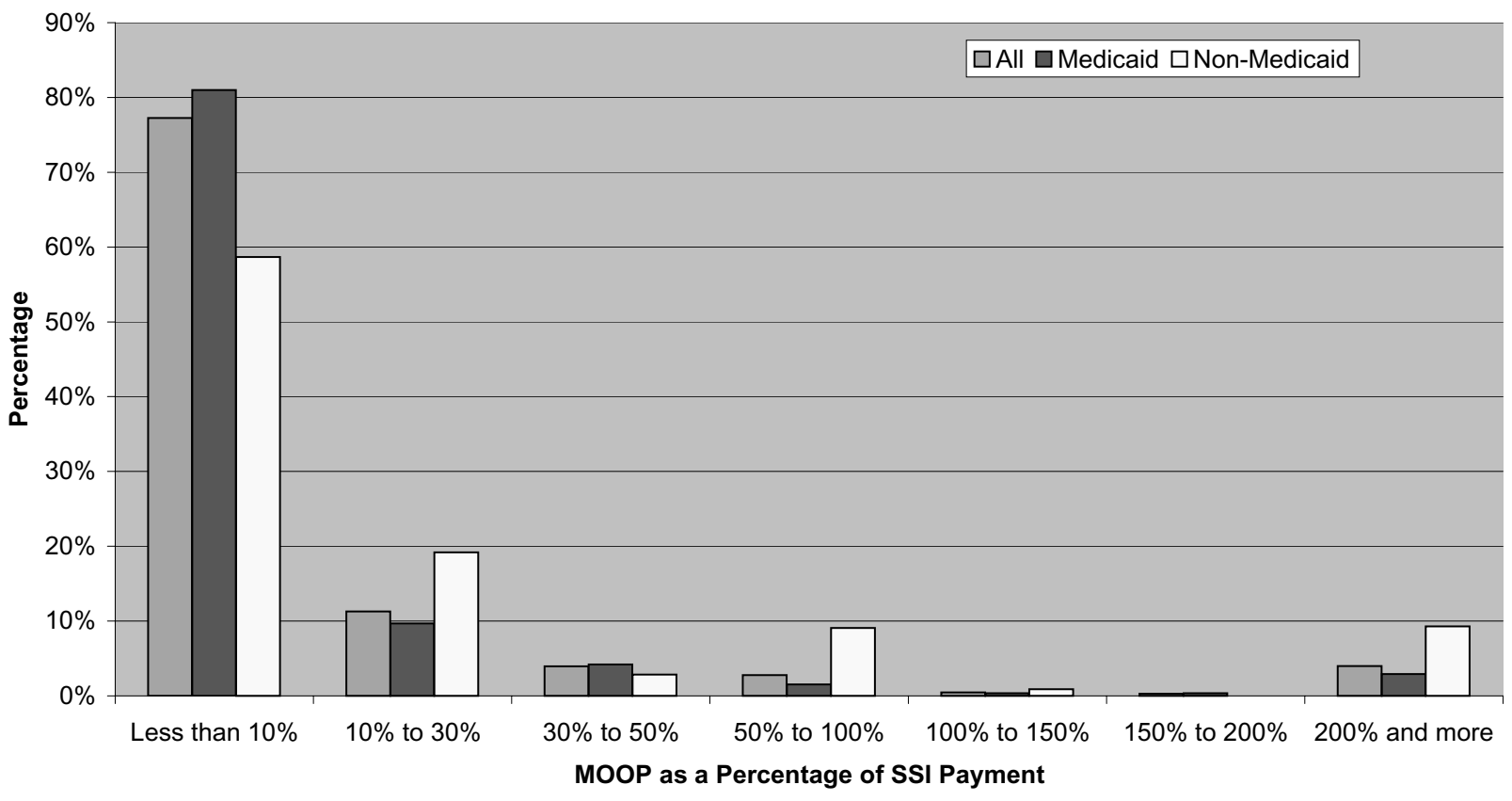

Source: Authors' calculations using the National Survey of SSI Children and Families.

Fig. 3. Percent with MOOP as a Percentage of SSI Payment Amount, by Type of Health Insurance (weighted, conditional on having MOOP expenses).

(16 percent). Only five percent of respondents indicated they would spend more on the child's disability with any portion of the $\$ 100$; even fewer indicated their first expenditure would be on the disability. Interestingly, those with a reported unmet health care need are slightly less likely to increase disability-related spending, and to increase this spending first, than those without a reported unmet health care need. This is reversed when budget changes are broken down by the presence of MOOP expenses (not reported). While most families would not change their disability-related expenses directly, it is not possible to tell which of the other options are indirectly affected by the disability. For example, one of the reasons the family could be in debt is because of prior disability-related expenses.

Table 6 addresses a hypothetical income change in the other direction. If the family's monthly income was reduced by $\$ 100$, the majority of families would cut back on everything ( 30 percent), followed by personal items (14 percent), other unlisted items (13 percent), and food (12 percent). Less than one percent would cut back on disability-related expenses. The first cuts for most families would not be very specific. Twentyseven percent of families would first cut spending all around and another 27 percent would cut back on other non-listed expenses. There is no statistical difference in the percentage reporting they would spend less on disability equipment or services, overall or first, by the presence of an unmet health care need. These results highlight the fact that SSI children have many needs unrelated to their disability and indicate the relative unimportance of their disability expenditures in the family budget.

\section{Conclusion}

This paper has shown that the majority of SSI children do not have unmet health care needs (91 percent). While the fraction of children on SSI with unmet health care needs is larger than in the general child population, it is smaller than in the general population of children with functional limitations. Almost one-quarter of SSI children have medical out-of-pocket expenses; however, for the vast majority of children, SSI payments cover their MOOP expenses. Additionally, for almost 4/5 of child recipients, 90 percent of their SSI payment is used for purposes other than those directly related to their disability.

While Medicaid insurance significantly reduces the likelihood of child SSI recipients having an unmet health care need, all else equal, even Medicaid-insured 


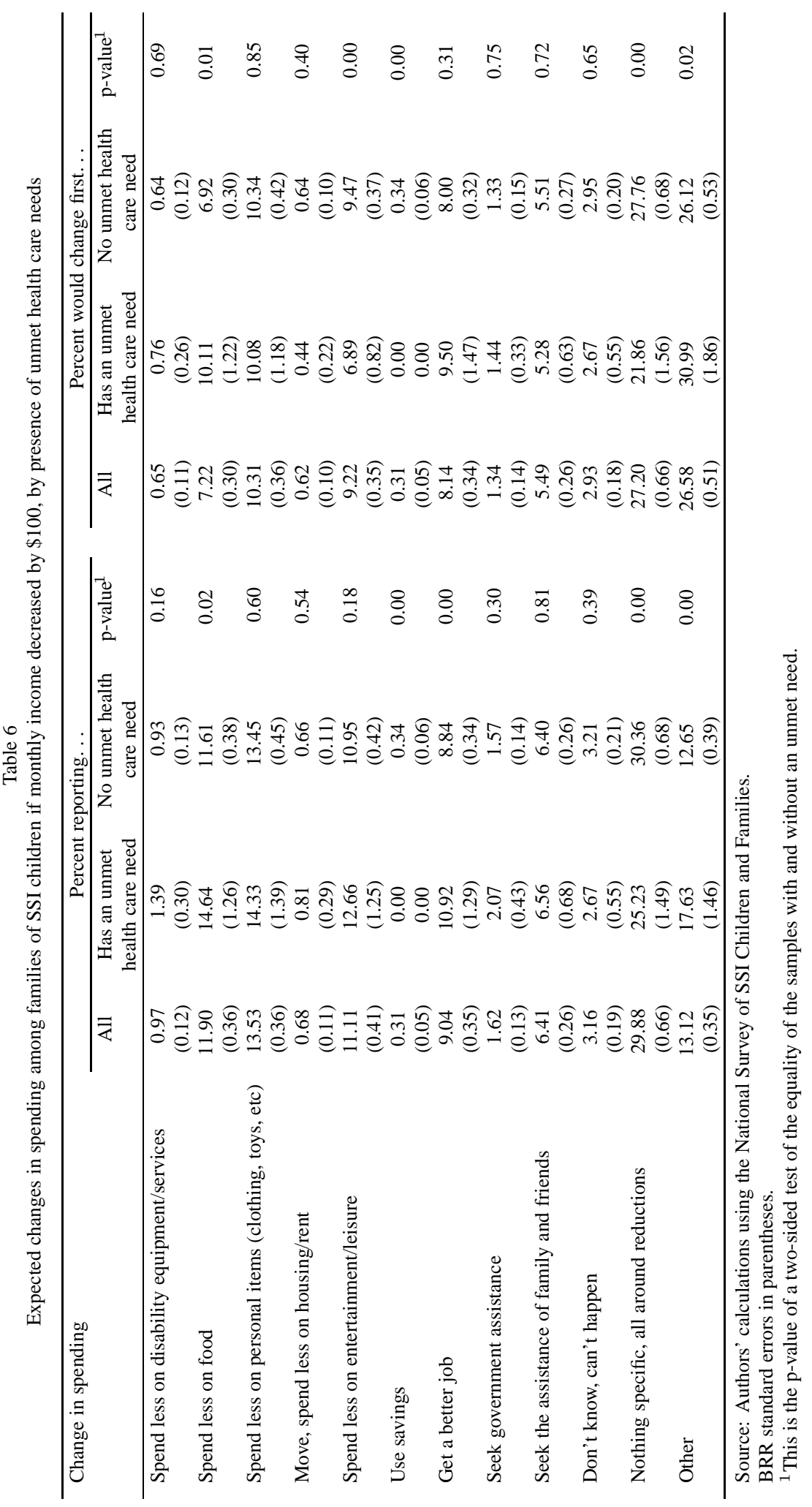


SSI recipients report financial barriers to health care access. Among recipients with an unmet need, those with non-Medicaid insurance are 1.5 times more likely to report cost as the cause for their unmet need, all else equal, compared to Medicaid-insured recipients. SSI recipients with non-Medicaid insurance are also more likely to report MOOP expenses, and for those that do, amounts are substantially higher than for Medicaidinsured recipients, all else equal.

Except for a small proportion with unmet needs, MOOP expenses for most SSI child recipients are substantially less than their SSI payment amounts. In addition to covering direct health care expenses, SSI benefits are also used to cover the child's other needs, including clothing, transportation, education, child care, and shelter, which are often much higher for disabled children. A child's disability may also limit a parent's ability to work, reducing the amount of income which can be earned to fulfill the child's needs, although there is some disagreement in the literature regarding this (see [7,14,25]). Many of these needs and other health care costs (such as dental care) are not necessarily incorporated in our measure of MOOP expenses.

There are several limitations of this analysis, its data, and the subject area of unmet needs and MOOP expenses. While the SSI payment is largely sufficient to cover MOOP expenses, the extent to which all disability related needs are covered by SSI is uncertain. Additionally, the degree of parents' subjectivity regarding the health of their child varies widely, and may produce biased estimates. More objective measures of unmet health care need, such as not seeing a doctor in the past 12 months or not having a regular doctor, may yield different results.

To identify the effects of SSI and Medicaid on the presence of an unmet health care need or MOOP expenses, a comparison group of non-Medicaid insured, non-SSI recipients is necessary. Because the NSCF does not include such a control, we limited our analysis to the SSI population. Future research should carefully consider other sources of data which can isolate the effects of SSI eligibility and Medicaid receipt. This might be particularly difficult because SSI receipt entails an almost automatic enrollment in Medicaid for most children.

As SSI children enter adulthood, many leave SSI voluntarily or are removed from the program because their disability does not match the criteria for SSI eligibility as an adult. Loprest and Wittenburg [15] have shown that many of these youth no longer have access to Medicaid or other forms of insurance. Because
Medicaid is so important in reducing unmet needs and MOOP expenses, several of these youth may eventually return to SSI due to poor health. Future work should consider whether increased levels of unmet needs and MOOP expenses persist for this group and whether this increases return to SSI later in life.

\section{Acknowledgements}

Special thanks to Paul S. Davies and Brett O'Hara, who originally worked on this topic, and Kalman Rupp, Paul S. Davies, L. Scott Muller, John Kearney, Susan Grad, Robert R. Weathers II, and Alexander Strand for their comments. The opinions and conclusions expressed are solely those of the authors and should not be construed as representing the opinions or policy of the Social Security Administration or the Office of Management and Budget.

\section{References}

[1] L. Aday and R. Andersen, A framework for the study of access to medical care, Health Services Research 9(Fall) (1974), 208220.

[2] Child and Adolescent Health Measurement Initiative, National Survey of CSHCN- Survey Instrument: NS-CSHCN 2001. Data Resource Center for Child and Adolescent Health website, 2007. Retrieved from http://cshcndata.org/ ViewDocument.aspx?item $=37$.

[3] J. Currie and L. Wanchuan, Chipping away at health: More on the relationship between income and health, Health Affairs 26(2) (2007), 331-344.

[4] P. Davies, K. Rupp and D. Wittenburg, A life-cycle perspective on the transition to adulthood among children receiving Supplemental Security Income payments, Journal of Vocational Rehabilitation 30(3) (2009), 133-151.

[5] P. Davies and K. Rupp, An overview of the National Survey of SSI Children and Families and related products, Social Security Bulletin 66(2) (2005/2006), 7-20.

[6] L. Dubay, J. Guyer, C. Mann and M. Odeh, Medicaid at the ten-year anniversary of SCHIP: Looking forward back and moving forward, Health Affairs 26(2) (2007), 370-381.

[7] M. Duggan and M. Kearney, The impact of child SSI enrollment on household outcomes, Journal of Policy Analysis and Management 26(4) (2007), 861-866.

[8] General Accounting Office (GAO), SSI children: Multiple factors affect families' costs for disability-related services, Publication number GAO/HEHS-99-99 Supplemental Security Income, 1999.

[9] R. Halvorsen and R. Palmquist, The interpretation of dummy variables in semilogarithmic equations, American Economic Review 70(3) (1980), 474-475.

[10] K. Heck and J. Parker, Family structure, socioeconomic status, and access to health care for children-research brief, Health Services Research 37(1) (2002), 173-186. 
[11] S. Kataoka, L. Zhang and K. Wells, Unmet need for mental health care among U.S. children: Variation by ethnicity and insurance status, American Journal of Psychiatry 159 (2002), $1548-1555$

[12] G. Kenney, J. Haley and A. Tebay, 2004, Awareness and Perceptions of Medicaid and SCHIP Among Low-Income Families with Uninsured Children: Findings from 2001. http://aspe. hhs.gov/health/reports/05/schipeval/FinalSlaitsPaper.pdf.

[13] C. Lewis, A. Robertson and S. Phelps, Unmet dental care needs among children with special health care needs: implications for the medical home, Pediatrics 116(3) (2005), 426-431.

[14] P. Loprest and A. Davidoff, How children with special health care needs affect employment decisions of low-income parents, Maternal and Child Health Care Journal 8(3) (2004), 171-182.

[15] P. Loprest and D. Wittenburg, Choices, challenges, and options: Child SSI recipients preparing for the transition to adult life, May 2005.

[16] A. Lukemayer, M. Meyers and T. Smeeding, Expensive children in poor families: out-of-pocket expenditures for the care of disabled and chronically ill children in welfare families, Journal of Marriage and the Family 62(2) (2000), 399-415.

[17] E. Maag, Supportive Health Services Needs of Children with Disabilities. US Department of Health and Human Services, 2000 . http://aspe.hhs.gov/daltcp/reports/suphsnd.htm\#note10.

[18] M. Mayer, A. Skinner and R. Slifkin, Unmet need for routine and specialty care: data from the National Survey of Children with Special Health Care Needs, Pediatrics 113(2) (2004), e109-e115.

[19] J. Mitchell and D. Gaskin, Do children receiving Supplemental Security Income who are enrolled in Medicaid fare better under a fee-for-service or comprehensive capitation model? Pediatrics 114(1) (2004), 196-204.

[20] P. Newacheck and M. McManus, Financing health care for disabled children, Pediatrics 81(3) (1988), 385-394.

[21] P. Newacheck, D. Hughes, Y. Hung, S. Wong and J. Stoddard, The unmet health needs of America's children, Pediatrics 105(4) (2000), 989-997.

[22] P. Newacheck, M. McManus, H. Fox, Y. Hung and N. Halfon, Access to health care for children with special health care needs, Pediatrics 105(4) (2000), 760-766.

[23] P. Newacheck, M. Inkelas and S. Kim, Health services use and health care expenditures for children with disabilities, Pediatrics 114(1) (2004), 79-85.

[24] P. Newacheck, Y. Hung, M. Park, C. Brindis and C. Irwin Jr., Disparities in adolescent health and health care: does socioeconomic status matter? Health Services Research 35(5) (2003), 1235-1252.

[25] E. Powers, Children's health and maternal work activity: Estimates under alternative disability definitions, The Journal of Human Resources 38(3) (2003), 522-556.

[26] K. Rupp, P. Davies, C. Newcomb, H. Iams, C. Becker, S. Mulpuru, S. Ressler, K. Romig and B. Miller, A profile of children with disabilities receiving SSI: Highlights from the National Survey of SSI Children and Families, Social Security Bulletin 66(2) (2005/2006), 21-48.

[27] K. Rupp and S. Ressler, Family caregiving and employment among parents of children with disabilities on SSI, Journal of Vocational Rehabilitation 30(3) (2009), 153-175.

[28] M. Rymer, M. Reither, R. Goldman and M. Van De Vanter, Survey of Blind and Disabled Children Receiving Supplemental Security Income Benefits, SSA Publication No. 13-11728, 1980 .
[29] Senate Committee on Finance, Personal Responsibility Act of 1995, 104th Congress, 1st session, Senate Report 96, 1995, 17-21.

[30] P. Sloper and S. Turner, Service needs of families of children with severe physical disability, Child Care Health Development 18(5) (1992), 259-82.

[31] Social Security Administration, Children Receiving SSI, Washington, DC: Office of Retirement and Disability Policy, Office of Research, Evaluation, and Statistics, 2001.

[32] Social Security Administration, Annual Report of the Supplemental Security Income Program, Washington, DC: Office of Policy, Office of Research, Evaluation, and Statistics, 2007.

[33] R. Thornton and J. Innes, Interpreting semilogarithmic regression coefficients in labor research, Journal of Labor Research 10(4) (1989), 443-447.

[34] US Department of Health and Human Services, National Center for Health Statistics 1999, NATIONAL HEALTH INTERVIEW SURVEY, 1996: ACCESS TO CARE SUPPLEMENT [Computer file]. ICPSR version. Hyattsville, MD: US Dept. of Health and Human Services, National Center for Health Statistics [producer], 1998. Ann Arbor, MI: Inter-university Consortium for Political and Social Research [distributor].

[35] US Department of Health and Human Services, Health Resources and Services Administration, 2007. EPSDT and Title $V$ Collaboration to Improve Child Health. http://www.hrsa. gov/epsdt/default.htm.

\section{Appendix A}

\section{Questions of primary interest in the NSCF}

The questions used to identify medical-out-of-pocket expenses are:

- Thinking about all the physical health care ("NAME") received in the past 12 months, about how much did ("YOU AND YOUR FAMILY") pay out-of-pocket for this care? Include all doctors visits, hospital stays, and prescription medicines. Do not include money that will be reimbursed by insurance or any other source. PROBE: Do not include money for mental health or substance abuse treatments. I'll ask about these later. Also, don't include money for dental care. (Question C9)

- About how much did ("YOU AND YOUR FAMILY") pay out-of-pocket for the ("MENTAL HEALTH"; "SUBSTANCE ABUSE"; "MENTAL HEALTH AND SUBSTANCE ABUSE") treatment that ("NAME") received in the past 12 months? Include both inpatient and outpatient care. Do not include money that will be reimbursed by insurance or any other source. (Question $\mathrm{C} 25$ )

The questions used to identify the presence of unmet needs are: 
Appendix Table A1

Insurance for part of the year, by insurance type and presence of unmet health care needs and MOOP expenses (row percentages)

\begin{tabular}{lcc}
\hline & $\begin{array}{c}\text { Percent insured } \\
\text { part of year }\end{array}$ & $\begin{array}{c}\text { Percent insured } \\
\text { all of year }\end{array}$ \\
\hline Total & $3.94(0.29)$ & $96.06(0.29)$ \\
By insurance status at time of survey & & \\
$\quad$ Medicaid & $3.84(0.28)$ & $96.16(0.28)$ \\
$\quad$ Non-Medicaid & $5.30(1.08)$ & $94.70(1.08)$ \\
By presence of an unmet need & & \\
$\quad$ No unmet need & $2.31(0.18)$ & $97.69(0.18)$ \\
$\quad$ Has unmet need & $19.61(2.10)$ & $80.39(2.10)$ \\
By presence of MOOP expenses & & \\
$\quad$ No MOOP expenses & $2.67(0.26)$ & $97.33(0.26)$ \\
$\quad$ Has MOOP expenses & $8.04(0.82)$ & $91.96(0.82)$ \\
By insurance status x unmet need & & \\
$\quad$ Medicaid with no unmet need & $2.32(0.18)$ & $97.68(0.18)$ \\
$\quad$ Medicaid with unmet need & $18.69(2.13)$ & $81.31(2.13)$ \\
$\quad$ NonMedicaid with no unmet need & $2.16(0.56)$ & $97.84(0.56)$ \\
$\quad$ NonMedicaid with unmet need & $29.49(7.19)$ & $70.51(7.19)$ \\
By insurance status x MOOP expenses & & \\
$\quad$ Medicaid with no MOOP expenses & $2.66(0.26)$ & $97.34(0.26)$ \\
$\quad$ Medicaid with MOOP expenses & $8.22(0.83)$ & $91.78(0.83)$ \\
$\quad$ NonMedicaid with no MOOP expenses & $2.93(1.05)$ & $97.07(1.05)$ \\
$\quad$ NonMedicaid with MOOP expenses & $7.16(1.73)$ & $92.84(1.73)$ \\
\hline
\end{tabular}

Source: Author's calculations based on the NSCF.

Note: BRR standard errors in parentheses

- People often delay or do not get needed health care. In the past 12 months, have you delayed or gone without health care for (NAME)? (Question C10)

- During the past 12 months, was there any time when ("NAME") needed prescription medicines but didn't get them? (Question C15)

Although the unmet need questions do not specifically mention health or substance abuse treatment, they are likely included in the more generic health care question.

Comparable Questions in the NHIS (U.S. Dept. of Health and Human Services 1999) and NSCSHCN (Child and Adolescent Health Measurement Initiative 2007)

The comparable questions from the NHIS (from National Health Interview Survey, 1996: Access to Care Supplement) identifying unmet needs are:

- "Sometimes people have difficulties in getting medical care when they need it. During the past 12 months, was there any time when someone in the family needed medical care or surgery, but did not get it?" (Question 11a)

- "During the past 12 months, was there any time when someone in the family needed prescription medicines but could not get them?" (Question 14a)

The comparable questions from the NSCSHCN (The National Survey of Children with Special Health Care Needs, 2001), also identifying unmet needs are:

- "People often delay or do not get needed health care. By health care I mean medical care as well as other kinds of care like dental care, mental health services, physical, occupational, or speech therapies, and special education services. In the past 12 months, have you delayed or gone without health care for (CHILD)?" (Question 44)

- "During the past 12 months, was there any time when (CHILD) needed, prescription medications? Did (CHILD) receive all prescription medications \{he/she $\}$ needed?

Why did (CHILD) not get the prescription medications $\{$ he/she $\}$ needed? Cost too much, health plan problem, not available in area/transport problem, not convenient times, doctor did not know how to treat or provide care, other" (Question 49a /b/c) 


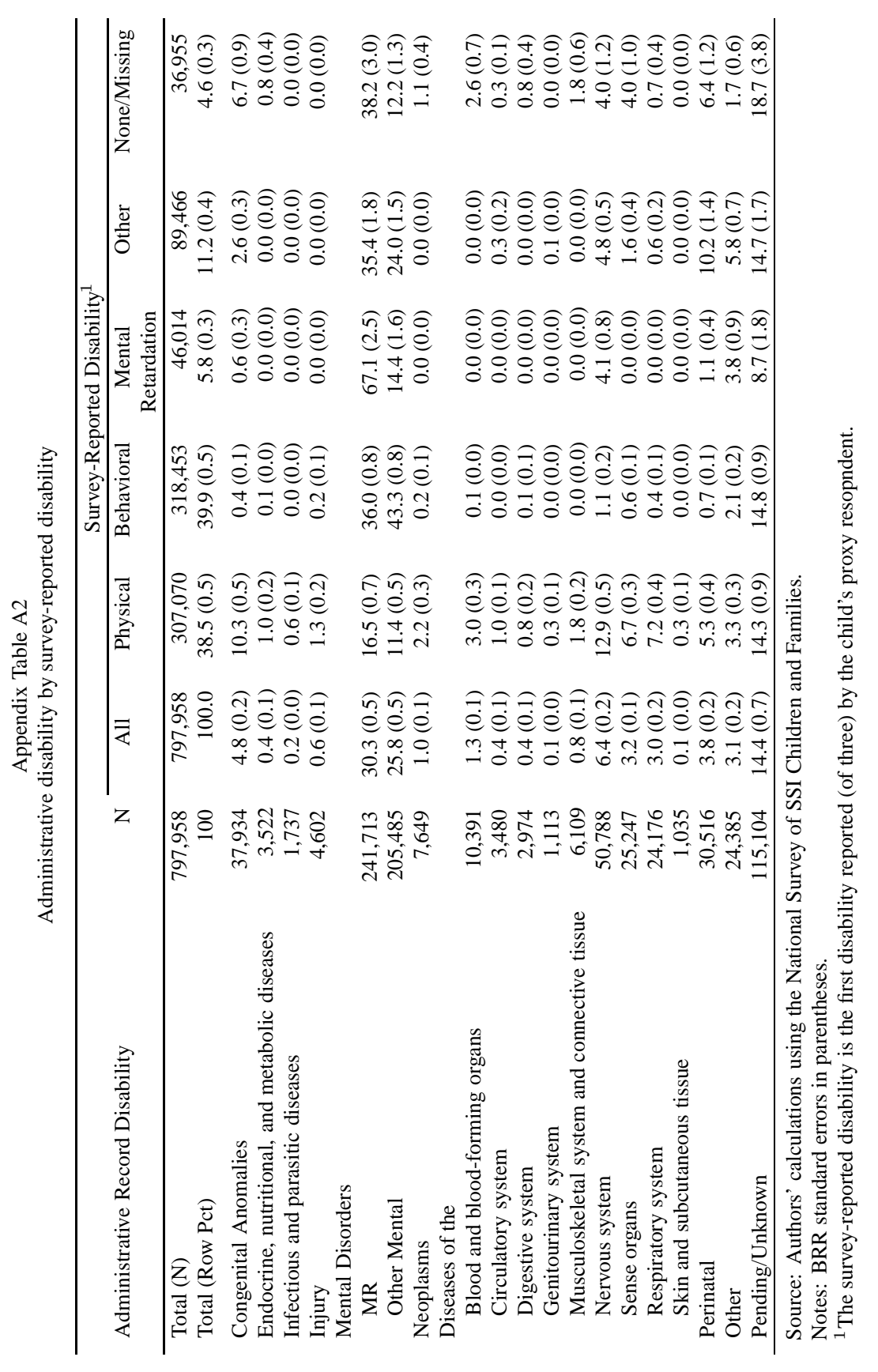

